\title{
Leadership Development of Technology Students Through Experiential Learning
}

\author{
Taciano M. Moraes* \\ *Instituto de Informática, Universidade Federal de Goiás, Goiânia, Brasil. \\ E-mail: tacianomoraes@inf.ufg.br \\ Leonardo G. de R. Guedes \\ •Escola de Engenharia Elétrica, Mecânica e Computação, Universidade Federal de Goiás, Goiânia, \\ Brasil. \\ E-mail: leonardoguedes@ufg.br \\ Sheryl Root ${ }^{\wedge}$ \\ ${ }^{\star}$ Integrated Innovation Institute, Carnegie Mellon University, Silicon Valley, USA. \\ E-mail: sheryl.root@sv.cmu.edu
}

\begin{abstract}
Numerous studies show that leadership is one of the factors that impact most on software projects' success. But even with more than U\$ 14 billion spent yearly on leadership development, it is worrying that more than half of the organizations still believe they are not doing it effectively. One of the most efficient methodologies used in companies is David Kolb's Experiential Learning, but still uncommon on Universities due to the difficulty of simulating practical experiences. Many approaches have been tried with various results and little standardization. For this reason, this study proposes a model for using group activities to help technology students practice leadership skills. A first pilot was executed with positive outcome but more experiments are necessary to ensure its application on other skills and contexts.
\end{abstract}

Keywords: Leadership, Higher Education, Experiential Learning, Alive Engineering, Project Management. 


\section{Introduction}

Combined with the inevitable digitalization of most markets, the cumulative complexity of software systems, and the globalization of teams, tech organizations are facing new leadership challenges in the 21st century. This context explains one of the reasons of why almost U\$ 14 billion is spent yearly on leadership development only in United States of America itself and increasing around $14 \%$ year-over-year ${ }^{1}$.

The other aspect is that the ways these professionals are developing their leadership skills are not being effective enough for all the above mentioned challenges. In spite of all this investment, a study by Bersin shows that almost $75 \%$ of leadership teams still fail to achieve business goals ${ }^{2}$ and a global survey done by Deloitte shows that $86 \%$ of companies consider leadership not only as their highest-priority issue but also the one with the largest gap to be fulfilled ${ }^{3}$.

An extensive research done in 195 countries by Gallup shows very alarming numbers: that only $13 \%$ of the employees are engaged at work, that disengagement drains almost U\$ 1 trillion worldwide per year, and that managers are ones responsible for $70 \%$ of their engagement ${ }^{4}$. The Ken Blanchard Companies estimate that superior leadership can reduce almost $9 \%$ in turnover rates, $5 \%$ to $10 \%$ in the productivity loss faced by companies and generate around $4 \%$ improvement in customer satisfaction, what reflects as $1.5 \%$ increase in revenue growth ${ }^{5}$.

For this reason, it is imperative that both companies and Universities assess and improve their ways of developing and teaching leadership, respectively. This study, however, will focus on the latter.

For many decades researchers and managers from all over the world have been trying to unveil the mystery behind the huge number of software projects that fail to meet schedule, budget, user satisfaction, quality, or even fail completely, being cancelled before delivering anything. One of the first and most successful on addressing this inherent difficulty of developing software was Frederick Brooks, with his book later being considered "the bible of Software Engineering" and introducing, possibly, the most breakthrough and at the same time ignored axiom:

"Adding manpower to a late software project makes it later" .

A decade later, the acclaimed book "Peopleware" argued that the major problems of software projects are not technical but rather human. It also presented the alarming statistic that from 500 projects surveyed from 1977 to 1987, the failure rate was of $15 \%$. For large projects it was even worst, $25 \%$ of them never completed, and most of the failure causes were someway related to leadership: communication problems, disenchantment with the boss, lack of motivation, and high turnover ${ }^{7}$.

Another study started in 1994 was even more drastic declaring that software development projects were "in complete chaos", with only $16 \%$ of them completing on-time and on-budget, $52 \%$ costing almost the double, and $31 \%$ being cancelled before the $\mathrm{end}^{8}$. The chart on Figure 1 exhibits a compilation of all the available reports until 2012, allowing a clear visualization of the evolution of the successes and failures of software projects. 


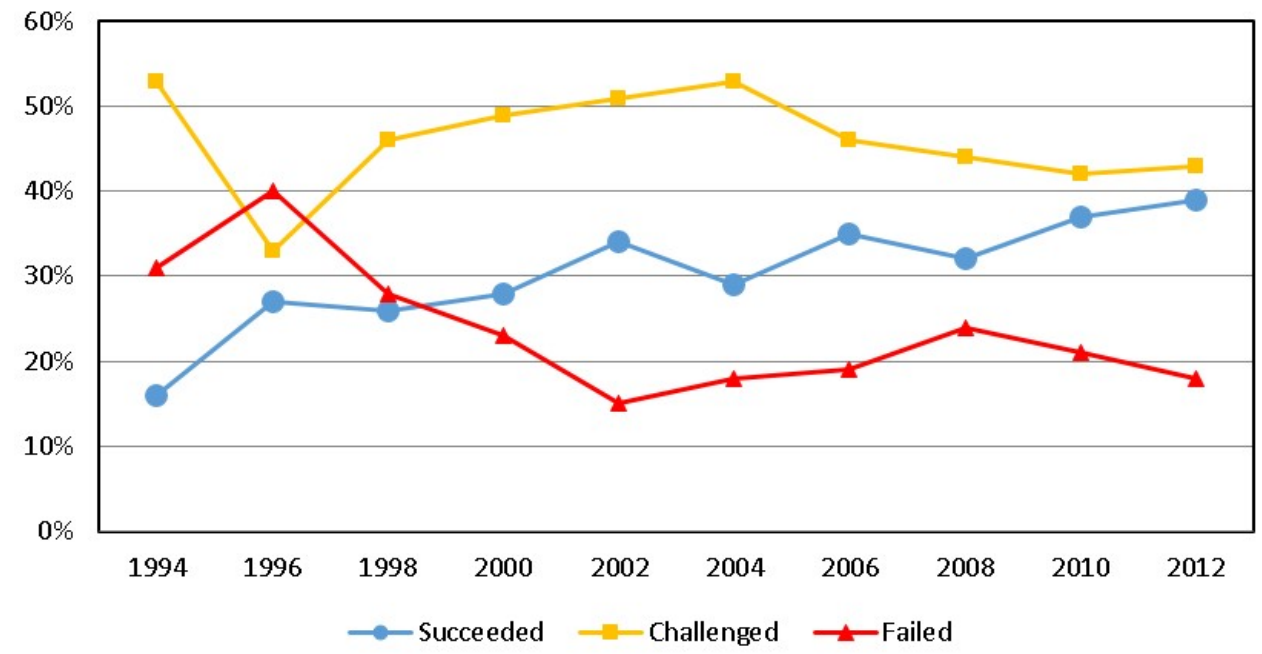

Figure 1. Software projects resolution results. Data extracted from ${ }^{9,10}$.

The trend on Figure 1 shows that projects failure rate has declined over the last decades, probably due to the adoption of OOP, IDEs, agile methodologies, continuous integration, and TDD, that minimized the accidental difficulties in software development. Nevertheless, the rate is still worrying precisely because the essential difficulties are the most impactful and complicated to deal with.

To study how Kolb's Experiential Learning could be used to give technology students a more practical experience on leadership courses taught in graduate schools.

Research questions: How are professors teaching leadership in technology Universities? What group activities are they using? How to use the Experiential Learning Theory to teach leadership?

Contrary to most of MBA students that usually work during their programs, already occupying management positions ${ }^{11,12}$ and can apply what they learn with leadership courses on their day-to-day jobs, technology students can't do alike and frequently struggle to implement what they learned in their professional or personal lives.

Because graduate students are mostly full-time and have zero or little leadership experience, they have limited and more difficult occasions to apply the leadership concepts they learn. Therefore, they will be the main focus of this study, which could be a significant opportunity to create value for a niche with an enormous need.

This work considers leadership as a powerful means to tackle the essential human difficulties of software development, which is also supported by a number of extensive studies that have shown that appropriate leadership not only decrease the risk of project failure but also significantly improve teamwork and staff productivity ${ }^{13}$. Therefore, improving the way technology Universities are teaching leadership today is a promising long-term endeavor to significantly increase the success rate (on Figure 1) to finally surpass the number of failed and challenged projects altogether. 


\section{Literature Review}

The queries were run with combinations of the keywords mentioned in Section 2 and also ad-hoc searches to find secondary references. Basically all the main queries (15 out of 16) combining all the three most important groups of keywords, returned no results when considering only the title, neither on Google Scholar or the University's library.

The exception was for the search string "Experiential Learning Leadership Software" that returned only two results and the first doesn't even cite Kolb. Because of this, a second search was run also considering other fields besides the title and returned a colossal number of results (hundreds of thousands), most of them with little or no relation to the subject of this study. From these, due to the time constraint of this study and the irrelevancy of the latest pages, only the 50 first results of each search string were considered to have their titles and abstracts analyzed, tunneling to a final number of 12 additional results that were moderately relevant.

\subsection{Directly Related Studies}

From the two directly relevant results obtained, the first one ${ }^{14}$ had precisely the same objective and approach of this study. The only difference is that they were implementing the Experiential Learning model not only in a single course but in a more systemic manner, spanning many leadership activities through the whole program.

In order to implement the Experiential Learning Theory (ELT) in their program, they reviewed how a few Universities such as MIT, Northeastern, Rice, and Penn State are already using it in their programs. As a result, they designed an integrated program that develops students using various methods since their start as freshman, to sophomore, junior and finally senior, each stage involving different activities.

From the challenges of the program and feedback from students, they identified six elements that can help on the implementation of an experiential learning approach:

1. "Leadership education should be implemented early on in an academic career;

2. Leadership education should be done in teams;

3. Active involvement of students allows them to take responsibility for their own learning and the learning of others;

4. Emphasis should be placed on skill building instead of knowledge acquisition;

5. Gradually withdraw support, as students are more comfortable; and

6. Debriefing is the most critical part of experiential learning".

The second study found ${ }^{15}$ was a mix approach of ELT, community service, and Problem Based Learning (PBL) on a course offered for technology programs. Although they didn't mention Kolb's model specifically, the course apparently fulfilled all the four learning modes as they offered a wide range of activities:

- Community service for the Junior Achievement program, serving as consultants for third and fourth grade children;

- Two days camp with indoor and outdoor leadership activities;

- Leadership seminars with reading assignments and industry guests' talks; and

- Problem Based Learning environment, with activities such as coaching a soccer team of thirteen-year old girls and being guest speakers in a monthly meeting of The Young Executive Association.

Besides the many challenges on implementing all these activities in a single course, they received widespread positive feedback on a survey to evaluate students' quantitative and qualitative reactions. As a conclusion, they suggest that this pilot course could not only 
be introduced in most Engineering and technology curricula but also broken into components to be incorporated in other programs.

\subsection{Indirectly Related Studies}

The other indirect results also explored numerous interesting approaches on how to use ELT. Although a good parcel of them was not specifically about leadership or for technology students, it is valuable to also present a brief discussion of the main highlights of them, once they can give other new perspectives to be experimented.

Similarly to the second study discussed on the previous section, that combined experiential learning with community service, three other articles also presented similar approach. One examined leadership programs from IBM and HSBC that collaborated with nonprofit organizations in order to develop the mindsets and skills needed for the leaders of a world with an increasingly need for sustainability, finding that the experiential factor was fundamental for the success of their outcomes ${ }^{16}$. The other two discussed on how service learning can not only cause a valuable impact on the community but also on students, acting as a powerful experiential approach with outcomes on their moral, social and leadership aptitudes ${ }^{17,18}$.

A study about the use of ELT on Management Education showed that tailoring the activities to span all students' learning styles has improved their academic excellence and also their attitude towards learning ${ }^{19}$. Other two used it on the teaching of Requirements Engineering, one focused on exercising IS developers' communication skills while presenting prototype ${ }^{20}$; and the other through the simulation of a business game where the students could experience the process and skills required with the purpose of easing their transition to the workplace ${ }^{21}$.

An Organizational Leadership program applied the ELT on a Research and Analytical Skills for Decision Making course, where they found that it can indeed boost significantly the amount of learning happened, but that it also requires a higher monitoring by the instructors, hindering the implementation in large classrooms ${ }^{22}$.

One of the articles mentioned the interesting use of Dramaturgical Teaching as a means to apply ELT ${ }^{23}$. Another remarkable use of an art-based leadership development, was one where business students had the opportunity to conduct a chamber choir ${ }^{24}$. This approach explored an important aspect that is commonly underestimated: "Leadership is an emotional, embodied, and interactive phenomenon between people". It is crucial to state the importance of social and emotional intelligences for leadership and not oversimplify it to a predominantly rational process.

One study on applying ELT in leadership coaching showed that it is possible for the Coach to make use of Kolb's Learning Style Inventory to assess the coachee's learning style and thus tailor the activities accordingly ${ }^{25}$. Another shows that even school leaders themselves are complaining that formal leadership development programs don't prepare them enough for the rigorous work of running the schools and requiring more personalized and practical ways to develop leadership for their jobs ${ }^{26}$.

Finally, the last study was selected with the intent to expand on the discussion about the gender gap on leadership. According to it ${ }^{27}$, the experiential components of leadership courses (e.g. volunteer service, studying abroad, and internships) can result just as much into leadership outcomes as into identity development for female leaders. 


\section{Methodology and Results}

Initially, a secondary research was done in order to better understand how professors are currently teaching leadership and if they are using any kind of practical activities to enhance students' learning. After ELT was adopted, a literature review was done to gather knowledge around this subject.

The two main sources for the desk research were Google Scholar and the University's digital library, once they essentially crawl most of the journals, academic databases, and online libraries. However, a few quick searches were also done in Google, specially relating to the activities. For this study, only the results integrally available were considered and the queries were assembled by combining the following keywords:

- "Leadership", "Leaders";

- "Experiential Learning", "Kolb", "Learning Style Inventory";

- "Software", "Technology", "Computing", "Information Systems";

- "Teaching Leadership", "Developing Leadership", "Leadership Learning"; and

- "Group Activities", "Team Activities", "Practical Activities".

Once the initial literature review was finished, a list of leadership group activities was compiled and one of them selected to be implemented using the ELT framework. A few details of the activity were slightly modified to match the new structure, but the general idea of the activity remained the same.

Following an Observational Methodology, the selected group activity was executed with a small number of students $(N=12)$ and entirely recorded on video, in order to allow a comprehensive Interaction Analysis (i.e. not only dialogues, but also gestures, usage of the provided materials, and body language) among the students and how the leadership process actually occurred and changed over time.

The population of students $(N=12)$ was between 20 to 30 years old, being 7 women $(58 \%)$ and 5 men $(42 \%)$, and most of them had little or no leadership experience. From their demographics, it is important to highlight that there was an immense discrepancy regarding their nationalities: 9 of them were Indian (75\%), 1 Chinese $(8.3 \%), 1$ Greek $(8.3 \%)$ and 1 Iranian $(8.3 \%)^{28}$.

After the execution of the pilot, all the findings and results about the use of this framework were collected and discussed (Sections 4 and 5).

\subsection{Results from Group Experiment}

After the group activity was completed, the students filled a form for evaluation and feedback based on a model ${ }^{29}$ to assess the following aspects:

- How much the students enjoyed the activity;

- How much knowledge and ideas they acquired with it;

- How much they will use in their lives what they learned;

- How much they think the activity improved on their results as leaders; and

- How much they put into practice of each related skill of the activity.

The only addition to the template provided was the last topic, where they could evaluate how much of each of the skills related to the activity was really practiced during the experiment. This change might be valuable with many activities, so the professor can keep track of the most effective ones. All the questions were objective with four alternatives to choose (as presented on Figure 2) and a textbox for subjective answers, where they could describe the highlights or suggest improvements. 


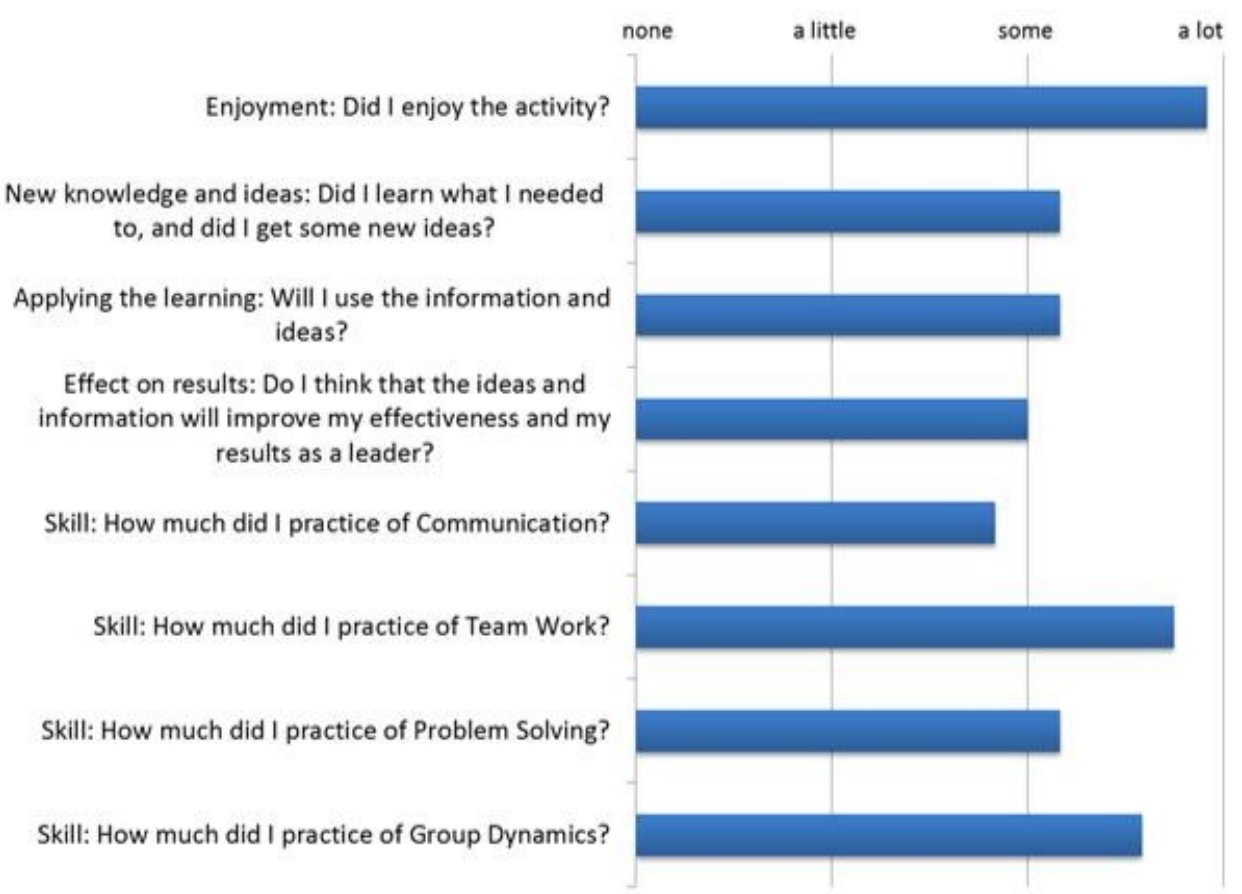

Figure 2. "Build the pyramid" activity evaluation.

The feedback shows that virtually all the students (91\% with 0.27 deviation) enjoyed the activity but 3 of them ( $25 \%$ with 0.91 deviation) were not sure on how it could improve their effectiveness as leaders. They found that the most practiced skill was Team Work (0.59 deviation) and the least was Communication (0.37 deviation).

The fact that this experiment was conducted outside the context of a Leadership classroom might have impacted on the answers, once they probably didn't have a clear view of what exactly they were learning, how to apply these skills in real life, and how they could improve their effectiveness as leaders, which are related to the questions 2,3 , and 4 . For this reason, these results need to be revalidated by professors in leadership courses in order to assure their accuracy relative to the real environment.

The next section will discuss in deep the results of this evaluation, as well as explore the particularities of the experiment and elaborate on the application of the ELT as a framework for leadership group activities.

\section{Discussion}

In the beginning of the activity, the students were asked to self-divide themselves in two groups, the first of which had 4 men and 2 women (Group 1), while the second had 5 women and 1 man (Group 2). This proportion coincidence in Group 2 allowed signs of the leadership gender gap to occur on their team, where the only man was the one guiding most of the actions of the group, although possibly unconscious of what he was doing. Another interesting observation related to gender was that, in both groups, the men were more focused on the action and the women were the ones who stopped what they were doing and thought on building the tool to improve their efficacy on carrying the cups. Evidently, these happenings might change depending on the context, culture, and personalities of the participants, and thus should not be considered as a general rule. Nevertheless, it was interesting to see that 
such a trivial group activity still reflected the same disparity we see in most organizations and societies, raising the urge for actions and programs to reduce it.

The Observational Methodology evidenced that both teams made no plan before starting their work and even though it was mentioned several times that they were supposed to build a tool to assist their job, still, the Group 1 on their first try used mostly the strings themselves to carry the cups and mount the pyramid. One of them even mentioned that "everyone had a different tool", what suggests that they were entirely driven by the competition with the other team, no matter the tools or the efficiency. This led them to failure on their first try, which supports the value of a leader that can think and plan on the run about efficacy, objectives, and restrictions.

However, the observation of high energy on both teams was a positive indicator that: "they have taken their group work seriously and their ability to tackle even more difficult learning tasks has been significantly enhanced"30.

Through the Interaction Analysis it was also possible to witness that, although the communication process (i.e. dialogues and discussions) was relatively democratic and decentralized, the coordination process (i.e. guiding the actions) was mostly done by one or two on each team, while the rest was basically following the orders. This indicates that the leadership process really happened but that only a few students could really experience leadership in practice, which is not necessarily a downside, as this prepares them for facing the same process everywhere else.

Regarding the leadership styles described by Daniel Goleman ${ }^{31}$, it was possible to visualize, by the group dynamics and body language, that the two major styles used by them were the Democratic and the Pace-setting. These styles might vary according to the type and mechanisms of the group activity or even to the individual personalities in the group, and because of this, more research is needed to establish any correlations among these.

\subsection{Classroom Evaluation}

Using the classroom assessment model ${ }^{32}$ combined with the Interaction Analysis of the video, it was possible to evaluate their behavior during the activity and all the aspects regarding the task, the instructor and the students. The results of this analysis are presented on Figure 3. 


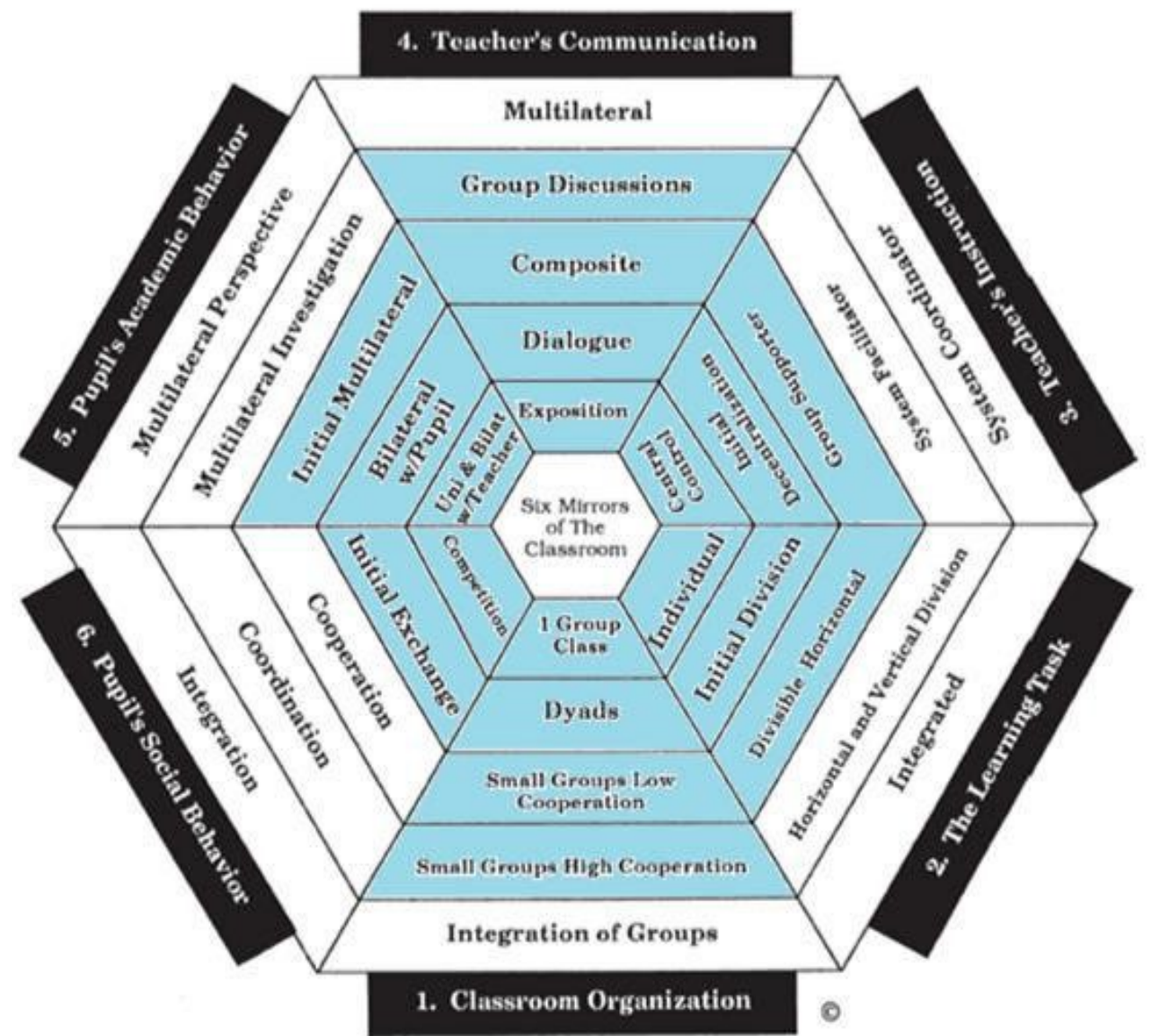

Figure 3. Evaluation of the Six Mirrors of the Classroom ${ }^{32}$.

In overall the result was satisfactory, with most of the grades above average. The classroom organization was of 'small groups with high cooperation'; Instead of an individual learning task, the activity allowed the students to work on a horizontal division; Due to the nature of the task, the instructor could act as a group supporter; The communication in the classroom happened in group discussion instead of a common exposition; The academic behavior of the students was on an initial multilateral level, rather than unilateral or bilateral; Only their social behavior that was not the most desirable, where the teams mostly competed against each other (sometimes even making fun with the opposite team, although in a playful way rather than mockery), having an initial exchange only during the discussions.

\subsection{ELT Framework for Leadership Group Activities}

Based on the adaptation of the schedule to match Kolb's Experiential Learning Theory, it is possible to elaborate a more generalized version that could match most kinds of leadership group activities. This framework (depicted on Figure 4) has the intent to help professors to make use of the ELT model to explore all the different learning styles in a structured approach, thus allowing students to also improve their least explored style. 


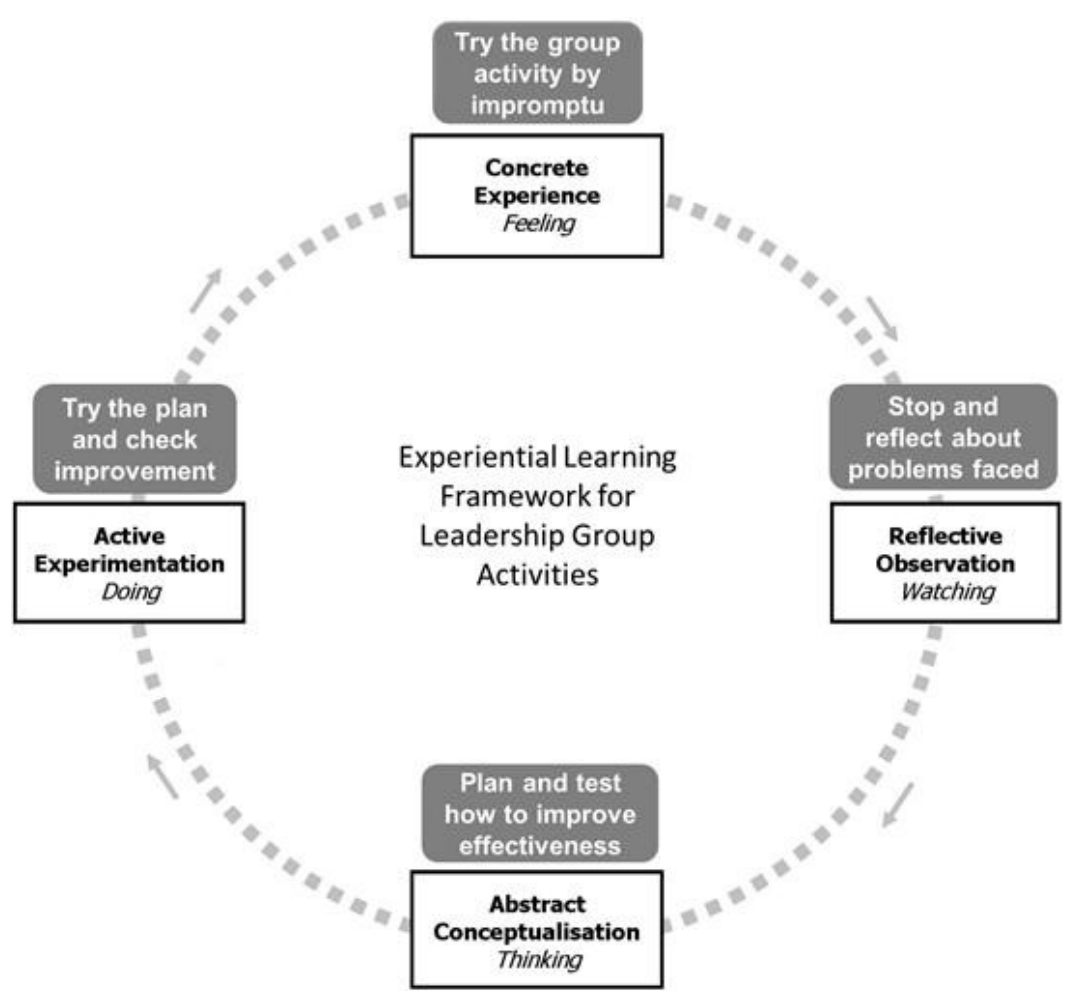

Figure 4. Model of framework to use ELT for leadership group activities.

The fundamental premise of this leadership group activity framework is on exploring the impromptu experience of the students; then make them reflect about the problems; learn with their mistakes and plan ways to improve; and finally experiment with the plan to check if they really learned a more effective way. Through these four different learning styles implemented on the group activities, students can have a more complete and deeper experience, therefore learning better.

\section{Conclusions}

It is evident that simple group activities, like the one presented on this study, are far from enough to make students master such complex and time-consuming to learn skills. This work has the modest ambition of merely presenting a realistic and structured alternative that is just better than the traditional way of teaching leadership. The intent was to introduce a framework that is both effortless and inexpensive to apply, to serve as a transition to adopting practical learning methodologies without needing vast cultural changes on the University or large budget approvals.

Another approach could be to use other courses' projects to practice these leadership skills, with small tasks to accomplish inside their other teams. The problem with this approach is that students still feel "carrying their past with them" and thus struggle to implement any change with their teammates that already knew them. With fast and simple activities, as the one examined, they are allowed to be "a new person" even that only for a brief moment, and hence try other approaches, behaviors, and skills.

A hybrid approach between these two ways could also be a good alternative to allow them to "be a new person" at the same time that they try to "change who they are" for team- 
mates. This way they could have these rapid experiences as a laboratory to exercise these new skills and later apply them on their real lives, learning about the extra complications.

Nonetheless, the students' evaluation of the pilot was certainly positive. The Interaction Analysis showed that the students truly dived into the experience and most of them could live brief moments leading inside their teams. Regarding the skills, it is clear that they had the chance to experience some amount of each skill involved in the group activity, and it is reasonable to predict that on a more complete leadership course they would feel even more confident to practice what they already learned.

Some limitations within this work are:

- Little time and resources to conduct more complete experiments with a larger number of activities, to compare the similarities of the results and discuss the particularities of each;

- The instructor (the author) had limited practice in running group activities, better results might be achieved by experienced professors;

- The impact of a prevalent culture in the activity is unknown and would require a more profound study in order to asses if it would be positive, negative, or irrelevant; and

- Once the framework was built from the lessons of a single experiment, it still lacks significantly more validation in order to be in a stage that it can be widely adopted in technology Universities.

For this study to be well accepted by the academy, these experiments should be replicated with larger groups, more activities and other contexts. Therefore, this would be the biggest priority for a future work.

Besides the validation of the framework, a deeper analysis of the impact of these leadership group activities on these students on the future, when they are already leading, is also crucial for the evolution of this study. It could reveal which activities were most effective and how exactly they impacted the students on the long term.

\section{Reference}

1. O' LEONARD, K.; LOEW, L. Leadership Development Factbook 2012. Bersin. Available in: $<$ https://www.bersin.com/Store/Details.aspx?docid=15587>. Accessed on: 15 Apr. 2019.

2. GARR, S.; LOEW, L. High Impact Leadership Development. Bersin. Available in: $<$ https://www.bersin.com/Practice/Detail.aspx?id=14449>. Accessed on: 15 Apr. 2019.

3. DELOITTE CONSULTING LLP AND BERSIN. Leaders at all levels: Close the gap between hype and readiness. Deloitte University Press. Available in: <https://www2.deloitte.com/insights/us/en/focus/human-capital-trends/2014/hc-trends2014-leaders-at-all-levels.html>. Accessed on: 10 Apr. 2019.

4. GALLUP. State of the American Manager: Analytics and Advice for Leaders, 2013.

5. The High Cost of Doing Nothing: Quantifying the Impact of Leadership on the Bottom Line. The Ken Blanchard Companies. Available in: $<$ http://www.kenblanchard.com/img/pub/Blanchard_The_High_Cost_of_Doing_Nothing. pdf $>$. Accessed on: 15 Apr. 2019.

6. BROOKS JR, F. P. The Mythical Man-Month and Other Essays on Software Engineering. $2^{\mathrm{a}}$ ed. Campus, 1974.

7. DEMARCO, T.; LISTER, T. Peopleware: productive projects and teams. New York: Dorset House Publishing Company, 1987.

8. THE STANDISH GROUP: The CHAOS Report (1994). Available in: $<$ https://www.standishgroup.com/sample_research_files/chaos_report_1994.pdf $>$. Accessed on: 12 May 2019.

9. EVELEENS, J.; VERHOEF, C. The rise and fall of the Chaos report figures. IEEE Software, v. 27 , n. 1, p. 30-36, 2010. 
10. THE STANDISH GROUP: CHAOS Manifesto 2013: Think Big, Act Small. Available in: < https://www.immagic.com/eLibrary/ARCHIVES/GENERAL/GENREF/S130301C.pdf >. Accessed on: 12 May 2019.

11. HUSSEY, A. The effect of ethics on labor market success: Evidence from MBAs. Journal of Economic Behavior \&S Organization, v. 80, n. 1, p. 168-180, 2011.

12. MORAES, T. M.; GUEDES, L. G. R. Developing Student Leadership through Experiential Learning. In: INTERNATIONAL CONFERENCE ON ALIVE ENGINNERING EDUCATION, 2018, Puerto Iguazú. Electronic Proceedings... Goiânia: Gráfica UFG, 2018. p. 81-82. Available in: < https://icaeedu.emc.ufg.br/p/27041-icaeedu-2018-publications $>$. Accessed on: 4 Jun. 2019.

13. TURNER, J. R.; MÜLLER, R. The Project Manager's Leadership Style as a Success Factor on Projects: A Literature Review. Project Management Institute, 2005.

14. WARNICK, G.; SCHMIDT, J.; BOWDEN, A. An Experiential Learning Approach to Develop Leadership Competencies in Engineering and Technology Students. ASEE Annual Conference, Indianapolis, 2014.

15. KRUPAR, J.; SUCKARIEH, G. Leadership And Teamwork Education For Engineering And Technology Students. ASEE Annual Conference, Portland, 2005.

16. GITSHAM, M. Experiential learning for leadership and sustainability at IBM and HSBC. Journal of Mgmt Development, v. 31, n. 3, p. 298-307, 2012.

17. SMITH, T.; ROSSER, M. Leadership Development through Experiential Learning. Association of Leadership Educators Conference, Ft. Worth, 2007.

18. GUTHRIE, K.; JONES, T. Teaching and Learning: Using Experiential Learning and Reflection for Leadership Education. New Directions for Student Services, v. 2012, n. 140, p. 53-63, 2012.

19. PENGER, S.; ZNIDARSIC, J.; DIMOVSKI, V. Experiential Learning And Management Education: Empirical Research And Implications For Practice In Higher Education In Slovenia. International Journal of Management and Information Systems, v. 15, n. 1, p. 23-34, 2011.

20. QURBAN, M.; AUSTRIA, R. Improving the Communication Skills of IS Developers during Requirements Elicitation Using Experiential Learning. Journal of Information Systems Education, v. 20, n. 3, p. 301-311, 2009.

21. REGEV, G.; GAUSE, D.; WEGMANN, A. Experiential learning approach for requirements engineering education. Requirements Engineering, v. 14, n. 4, p. 269-287, 2009.

22. BANGS, J. Experiential Learning in an Organizational Leadership Program. Journal of College Teaching \& Learning, v. 8, n. 10, p. 29-34, 2011.

23. BARBUTO, J. Dramaturgical Teaching in the Leadership Classroom. Journal of Leadership Education, v. 5, n. 2, p. 4-13, 2006.

24. SUTHERLAND, I.; JELINEK, J. From Experiential Learning to Aesthetic Knowing: The Arts in Leadership Development. Advances in Developing Human Resources, v. 17, n. 3, p. 289-306, 2015.

25. TURESKY, E.; GALLAGHER, D. Know thyself Coaching for leadership using Kolb's Experiential Learning Theory. The Coaching Psychologist, v. 7, n. 1, p. 5-14, 2011.

26. ZHANG, W.; BRUNDRETT, M. School leaders' perspectives on leadership learning: the case for informal and experiential learning. Management in Education, v. 24, n. 4, p. 154-158. 2010.

27. BELTON, R. The impacts of experiential learning on leadership identity in female college graduates. (PhD Dissertation) - University of North Carolina, Greensboro, 2010.

28. MORAES, T. M.; GUEDES, L. G. R. Developing Student Leadership through Experiential Learning. In: DEUS JUNIOR, G. A. de et. al. (Org.). Alive Engineering Education: Integrating and Innovating Engineering Education in Favor of Society. Goiânia: Gráfica UFG, 2019. cap. 38, p. 401-410. Available in: < https://icaeedu.emc.ufg.br/p/27041-icaeedu-2018-publications $>$. Accessed on: 4 Jun. 2019.

29. CHAPMAN, A. Donald Kirkpatrick's Learning Evaluation Theory: Businessballs. Available in: <http://www.businessballs.com/kirkpatricklearningevaluationmodel.htm>. Accessed on: 23 May. 2019.

30. TANG, J.; LEIFER, L. An Observational Methodology for Studying Group Design Activity. Engineering Design, v. 2, n. 4, p. 209-219, 1991. 
31. GOLEMAN, D.; BOYATZIS, R.; MCKEE, A. Primal leadership: Realizing the Power of Emotional Intelligence. Harvard Business School Press, 2002.

32. LAZAROVITS, R. H.; MILLER, N. Interaction in Cooperative Groups. Cambridge University Press, 1992. 
